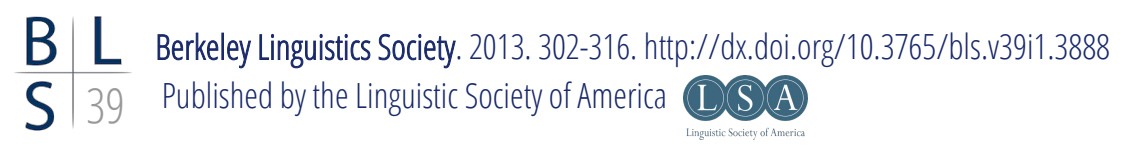

\title{
Possession as Non-Verbal Predication
}

\author{
Shiao Wei Tham \\ Wellesley College
}

\section{Introduction}

This paper argues that crosslinguistic variation in the forms of clausal possessive predication (1-2) arises to a large extent from the NON-VERBAL nature of possessive predication.

(1) raam-ke paas ek hii makaan hai

Ram-OBL.GEN near one only building be-PR ${ }^{1}$

Ram has/owns only one building. Indefinite possessive predication (Hindi: Mohanan 1994:179, (63))

(2) This pen is Pat's. Definite possessive predication

As evidence, I demonstrate that possessive predication across languages shows all the variation possible for non-verbal predication in general. I show the nonverbal approach not only accounts for previously observed major strategies in possessive predication, for both INDEFINITE (1) and DEFINITE (2) possessive predication (also known respectively as HAVE and BELONG possessives), it also predicts the availability of "minor", less-frequently observed encoding strategies.

${ }^{1}$ Abbreviations: $1 / 2 / 3=1$ st, 2nd, 3rd person; ADESS = adessive; $\mathrm{CL}=$ classifier; $\mathrm{DAT}=$ dative; $\mathrm{DEF}$ = definite; FEM = feminine; GEN = genitive; INSTR = instrumental; $\mathrm{ND}=$ non-determinate; $\mathrm{NOM}=$ nominative $; \mathrm{OBL}=$ oblique $\mathrm{PR}=$ present $\mathrm{SG}=$ singular; $\mathrm{SJ}=$ subject. 
Before proceeding, a caveat: Possession may certainly be verbally expressed, e.g. English own, belong, Japanese motu 'own', but not all languages have possessive verbs. In contrast, both in languages with and without such verbs, non-verbal possessive structures such as (1) and (2) may occur.

In the next two sections, I provide background on crosslinguistic variation in both the forms of possessive predication (Section 2) and non-verbal predication (Section 3). Section 4 shows that possessive predication manifests all the variation of non-verbal predication structures. Section 5 concludes.

\section{Variation in possessive predication}

This section introduces crosslinguistic variation in the forms of possessive predication through the lens of two important works. Heine (1997) is concerned with the conceptual sources of possessive morphemes. Stassen (2009) proposes a typology of indefinite possessive predication clauses.

\subsection{Possessive morphemes have different metaphorical sources}

One major source of crosslinguistic variation in possessive predication is that possessiveencoding morphology may have its source in other conceptual categories. Heine (1997) identifies eight "event schemas" for possessive predication:

(3)

\begin{tabular}{ll}
\hline Formula & Label of event schema \\
\hline X takes Y & Action \\
X is located at Y & Location \\
X is with Y & Companion \\
X's Y exists & Genitive \\
Y exists for/to X & Goal \\
Y exists from X & Source \\
As for X, Y exists & Topic \\
Y is X's (property) & Equation \\
\hline
\end{tabular}

(Heine 1997:47 Table 2.1)

Among these, locative morphology in possessive encoding, e.g. in Hindi (1) above is perhaps the best-known and most-discussed (Lyons 1968:388-399, Clark 1970, Freeze 1992, among others). This work takes for granted, and does not focus on, this variation in the conceptual categories of possessive-encoding morphemes.

\subsection{Variation in the forms of possessive clauses}

More directly relevant to the current discussion is Stassen's (2009) morphosyntactically(rather than conceptually-) based four-way typology of possessive predication, drawn from extensive crosslinguistic study. The four basic classes proposed are Locational, With, Topic, and Have possessives, described below. For reasons of space, each class is illustrated with only one language. Where possible, examples from other languages are given in later sections. 


\section{Possession as Non-Verbal Predication}

The Locational class may be exemplified by Finnish possessives, where the possesor (PSR) nominal shows locative marking (4a,b) (see also Hindi (1)), and the possessive sentence appears structurally parallel to an existential sentence (4c). Stassen includes in this class PSRs in genitive and dative case, so it is clear that, unlike Heine's approach, it is overt marking on the PSR, rather than the conceptual category of the marker, that defines Locational possessives.

(4) Finnish (Locational)
a. Kissa on mato-lla cat is mat-ADESS
b. Johni-lla on kissa John-ADESS is cat
The cat is on the mat. (Locative) John has a cat. (Possessive)
c. Mato-lla on kissa mat-ADESS is cat
There is a cat on the mat. (Existential) (Data from Paul Kiparsky, p.c.)

With possessives feature a possessee (PSE) nominal with comitative marking, e.g. a with adposition (5).

\section{(5) Amele (With) \\ Ija sigin ca \\ 1SG knife with}

I have a knife. (Roberts 1987:81, cited in Stassen 2009:56 (44))

In Topic possessives (6), the PSR and PSE nominals show no marking; the clause contains an existential verb, presumed to be intransitive. The PSR is assumed to be the topic and the PSE the subject.

(6) Mandarin (Topic)

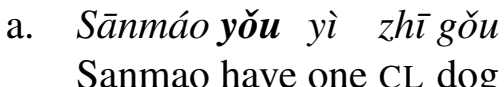
b. shù-xia yǒu yì zhīgǒu tree-below exist one CL dog
Sanmao has a dog. (Possessive) There is a dog under the tree. (Existential)

Finally, Have possessives (7) resemble Topic possessives in that the PSR and PSE nominals also show no marking. The main contrast between these classes is that the Have possessive clause contains a transitive verb typically descended from an Action verb of taking, seizing, grabbing etc.

\section{(7) English (Have): Pat has a dog.}

Stassen's categories correspond partially to Heine's. The main distinction between them is that Stassen's typology is confined to INDEFINITE POSSESSIVE PREDICATION (e.g. (1)) where the PSE nominal is canonically indefinite. Heine's includes DEFINITE POSSESSIVE PREDICATION (e.g. (2)), where the PSE nominal is 
canonically definite. Specifically, Stassen's Locational class covers Heine's Location, Genitive, Goal (and sometimes Source) ${ }^{2}$ possessives. Stassen's With possessives correspond to Heine's Companion schema. The Topic possessives in both proposals coincide, while Stassen's Have possessives are Heine's Action possessives. But Heine's Equation schema, which accounts for definite possessive predication, has no parallel in Stassen's system.

Stassen derives these four basic possessives and other less-frequently observed possessive encoding options from an analysis of indefinite possessives as underlyingly two existential clauses in a sequencing structure. Very briefly, possessive encoding correlates with (i) whether in a language, a temporally simultaneous clause sequence with different subjects consists of two independent clauses or if one of these clauses is subordinated; (ii) whether, in non-verbal predication, a language uses the same grammatical device (e.g. the same copula) in nominal and locative predication sentences. See Stassen (2009) Parts II-III, for the full exposition.

While the importance and scope of this work cannot be overstated, Stassen's approach leaves certain questions unanswered. For instance, it does not account for definite possessive predication. Furthermore, classifying languages as belonging to a particular typological class (Stassen 2009, 45) runs into the problem of multiple encoding strategies in the same language, whether for possessive predication, or for the proposed determinant structures such as simultaneous sequence clauses.

Implicit in Stassen's discussion is the idea that possessive predication is (at least sometimes) a non-verbal predication structure (see also Hengeveld 1992, 100). The consequences of this assumption have yet to be fully explored, though. Below, I propose that the non-verbal assumption alone accounts for much of the variation in the forms of possessive predication. I show that both indefinite and definite possessive predication clauses show the same range of variation as non-verbal predication structures. This approach is compatible with the existence of multiple possessive encoding strategies in one language. It further predicts the availability of lessfrequently observed possessive clause structures.

\section{Non-verbal predication}

Non-verbal predication structures (NVPSs) are those in which the semantic relation need not be expressed by a verb (Dik 1980, Hengeveld 1992). Across languages, NVPSs may vary according to (i) the morphosyntactic category of the predicate phrase; (ii) the predication type of the clause (ascriptive, equative, presentative); and (iii) the kinds of verbal elements such as copulas (if any) that occur in them, and their semantic contribution. I elaborate on each point below.

2 The Source schema is characterized by a PSR with ablative marking, and is mainly restricted to adnominal possessive expressions (Heine 1997, 64). 


\section{Possession as Non-Verbal Predication}

\subsection{Non-verbal predicate categories}

A non-verbal predicate may be nominal (8a), adjectival (8b), or an oblique phrase which shows some kind of adpositional or semantic case marking (8c).
(8) a. John is a carpenter.
b. Sheila is intelligent.
c. John is in the garden.
(Nominal)
(Adjectival)
(Oblique phrase)

Nominal predication expresses notional categories such as set membership (8a), class inclusion (e.g. A cat is an animal), and identity, e.g. John is my best friend.

Adjectives predicate a property of an individual (8b), while an oblique phrase may express a range of relations including locative (8c), possessive (9a), accompaniment $(9 b)$, benefit $(9 c)$ etc.
(9) a. This book is John's.
b. John is with Bill.
c. This book is for John.

\subsection{Predication type}

NVPSs also fall into different categories of PREDICATION TYPE. These categories have been given different labels. I follow largely (though not entirely) the use in Hengeveld (1992) of ASCRIPTIVE, EQUATIVE, and PRESENTATIVE.

In ascriptive sentences, a predicate meaning is applied to a subject. This would be the category of NVPSs such as (10) and (12), with the relatively standard semantic structures in (11) and (13) respectively.
(10) Jemima is a cat.
(11) $\lambda x[\operatorname{cat}(x)](j)$
(12) Jemima is in the garden.
(13) $\lambda x[$ ly $\operatorname{garden}(y) \wedge \operatorname{in}(y)(x)](j)$

NVPSs may also be equative, indicating that two descriptions of the same semantic type have the same denotation, e.g. the classic The Morning Star is the Evening Star. Now, NVPSs with two definite NPs may further differ in terms of whether they are specifying or characterizing (Higgins 1979, Hengeveld 1992, 8288), but it should be clear that at least a subset of sentences with two referring expressions of the same type can be interpreted as expressing identity. For instance, (14a) would have a semantic structure as in (14b).

(14) a. That dog over there is Fido. b. $\lambda y \lambda x[x=y](f)($ that.dog.over.there)

Finally, NVPSs may be presentative, the typical example being an existential sentence, e.g. There is a boy/someone/a strange book in the room. For current purposes, presentative sentences are best characterized in terms of their function, which I assume is to introduce or re-introduce an individual into the discourse. The definiteness effect (DE) exhibited by the post-copular nominal (the pivot) in an English there- existential is well-known (15).

(15) \#There is my sister/everyone/the strange book in the room. (Safir 1987, 71 (1)) 


\section{Shiao Wei Tham}

A copious literature exists on how best to formally characterize the NPs that occur felicitously in this position across contexts (Milsark 1974, Barwise and Cooper 1980, McNally 1997, among others). Formal properties aside, however, there is a general recognition that there is a pragmatic component to the DE (Barwise and Cooper 1980, Abbott 1992, McNally 1997, to name a few), which Abbott (1992:9) characterizes as functioning "typically to present items to the addressee".

Drawing on these insights, I adopt a working definition of "presentative" as any construction that imposes some condition of newness or unfamiliarity on one nominal in the construction. This condition may be realized differently in different kinds of sentences. In there existentials, this condition shows up in part as a formal condition on the pivot. In other kinds of presentative sentences, e.g. "presentational there-insertion" (16) (Aissen 1975) and locative inversion (17) (see e.g. Bresnan 1994), the condition applies to the information status of the postposed nominal (e.g. it cannot be the sentence or discourse topic).

(16) a. There hangs on the office wall a picture of Edward Sapir.

(Aissen 1975:1 (1))

b. There still stands on this desk the bowling trophy he won last year. (ibid.:2 (11)))

(17) a. In the corner was a lamp. (Bresnan 1994:75 (1b))

b. Among the guests was sitting my friend Rose. (ibid. (2b))

\subsection{Verbal elements in NVPSs}

NVPSs often contain a verbal element, although the role played by this element varies, and is not always obvious. Still, semantic relations expressed non-verbally in some languages (e.g. different kinds of property ascription, identity) may clearly also be encoded verbally either in the same language or in other languages.

\section{Copulas}

An NVPS may contain a copula (e.g. English be), often considered a semantically empty element, present only as a carrier of grammatical features such as tense (Lyons 1968, Dik 1980:94-98, Hengeveld 1992:73, Pustet 2003:3, though see Stassen (1997:65-76) for a critique).

Languages vary as to whether a copula is available. The copula may be verbal or non-verbal (and a bound or free morpheme) (Pustet 2003:41ff). In languages with a copula, the copula may be present or absent depending on the category of the nonverbal predicate, or on sentence tense category (Stassen 1997, 64). For instance, in Russian, NVPSs in the present tense do not allow a copula, but in all other tenses, the copula byt is required (Stassen 1997, 64). In Hungarian present tense NVPSs with a 3rd person subject, a copula is disallowed with a nominal predicate, but required for locative predication (Stassen 1997, 67). 


\section{Possession as Non-Verbal Predication}

\section{Light verbs}

In some languages, NVPSs of different morphosyntactic and predication categories use the same copula, e.g. English, French, Finnish. NVPSs in other languages, however, may show a "split" (Stassen 1997) based on the meaning expressed.

Often, there is a split between existential and non-existential predication (Stassen 1997). An example is Serbo-Croat, where nominal, adjectival, and locative predication show the copula biti "to be". Existential sentences employ the impersonal form of the verb imati "to have", with the presented theme occurring in the accusative case (Stassen 1997:10). In Mandarin, the copula shi 'be' is used in nominal predication (Li and Thompson 1981, 148), adjectival predication (p143) does not allow the copula. Existential predication uses the verb yǒu 'have/exist' (p509). Locative predication is expressed with the "coverb" zài 'be at', which shows properties of both verbs and prepositions (p356-369).

Below, I reserve the term COPULA for a verb or "linking word" in nominal predication, where one occurs. If a distinct word is used in existential predication, I refer to that word as a LIGHT VERB. This is because such verbs often evolve to express more abstract meanings, e.g. tense, aspect, modality (Heine 1997, 187ff). In what follows, I extend the range of NVPSs to include light verb predication structures (LVPSs) such as Serbo-Croat imati sentences and Mandarin yǒu sentences.

To sum up, NVPSs may vary by (i) morphosyntactic category of the predicate phrase; (ii) predication type (ascriptive, equative, presentative); (iii) whether a copula is present, and (iv) whether a light verb distinct from the copula is used.

\section{The non-verbal analysis of possessive predication}

I now return to possessive predication structures, showing that for both indefinite and definite possessive predication across languages, variation follows the lines drawn by NVPSs (including LVPSs). The non-verbal analysis also predicts the possibility of less-frequently observed possessive encoding options.

\subsection{Major classes: deriving Stassen's (2009) basic classes}

I first show how the major categories of indefinite possessive predication as identified in Stassen (2009) arise. Possession is a two-place relation, so we may reasonably expect two nominals in a possessive clause, the PSR and the PSE. Turning first to cases where there is no light verb, and where the NVPS contains an oblique phrase, this means oblique marking could fall on either PSR or PSE. ${ }^{3}$

Without further assumptions, this already gives us two major classes in Stassen's 2009 typology: Locational possessives (oblique marking on PSR) (4c) and With possessives (oblique marking on PSE) (5). Relevant examples from Finnish and Amele are repeated below.

${ }^{3}$ I presume there are general markedness restrictions against both PSR and PSE nominals showing oblique marking. 
Shiao Wei Tham

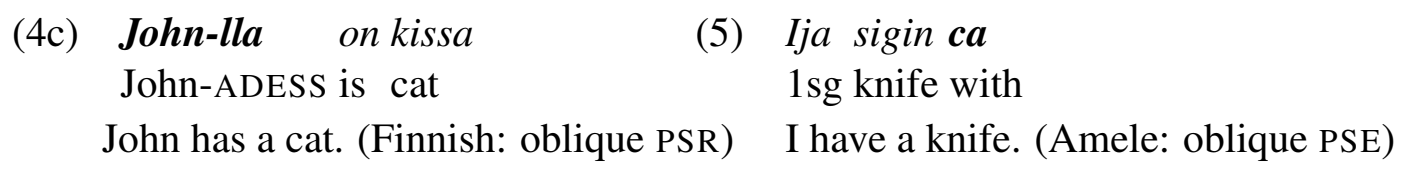

Alternatively, a light verb may be used. Disregarding whether the verb is "truly" transitive, this yields the other two members of the typology: Topic (18) (also (6)) and Have (19) (also (7)) possessives. ${ }^{4}$

(18) Ahmad ada kereta

Ahmad have car

Ahmad has a car.

(Malay: "Topic",

data from Hafizah Binte Jumat, p.c.)
(19)

Mannen ha-r en hund man.DEF have-PR a dog

The man has a dog.

(Norwegian: "Have" Stassen 2009:65

(87), data from Pål Kristian Eriksen)

\subsection{Presence of a copula}

As with other NVPSs, possessive clauses may or may not show a copula. This point is relevant only for cases where there is no light verb. Whether oblique marking occurs on PSR or PSE, there may or may not be a copula present. Both Finnish (4c) and Kabyle (20) possessives show oblique PSRs, but the former exhibits a copula while the latter does not. Similarly, both Amele (5) and Mbay (21) possessives mark the PSE, but a copula is present in the latter but not the former.

\section{yur-s takerrust tamellalt \\ at-him car white}

He has a white car. (Oblique PSR, no copula)

(Kabyle: Naït-Zerrad 2001:130, cited in Stassen 2009:79 (57))

(21) Ngōn ̌̌ kò kìyā

child is with knife

The child has a knife. (Oblique PSE, with copula)

(Mbay: Keegan 1997:77, cited in Stassen 2009:57 (52))

\subsection{Extending the major classes to definite possessive predication}

The same assumptions account for definite possessive predication (e.g. This pen is Pat's), which show almost all the same kinds of morphosyntactic variation.

Definite possessive predication may show oblique marking on PSRs, with the same range - locative (22), dative (23), genitive (24) - as indefinite possessive predication. Again, a copula may be present ((22), (24)) or not (23), but for lack of space, I do not provide examples for each case marker.

(22) Le livre est ̀̀ Jean.

the book is at/to Jean

The book is Jean's. (French: Locative PSR, Clark 1970:1 (4b))

${ }^{4}$ Malay has no overt copula in nominal predication sentences, $a d a$ is also the existential verb. 


\section{Possession as Non-Verbal Predication}

\section{(23) Kamirri yila manin-ji \\ that dog woman-DAT}

That dog is the woman's. OR That dog belongs to the woman.

(Nyikina: Dative PSR, Stokes 1982:398, cited in McGregor 2001:342 (12))

\section{(24) liber est Marc-i \\ book be.3SG.PR Mark-GEN}

The book belongs to Mark. (Genitive PSR, Latin: Seiler 2001:33 (1b))

There are also cases of definite possessive predication realized with a light verb. Akan employs a light verb (distinct from the copula in nominal predication) in definite possessive predication (25). Indefinite possessives in Akan use the - almost identical - existential and locative verb wò, which has a different tone (Boadi 1971).

(25) ntamá no wó sbarimáa no

cloth that be POSS man that

The cloth belongs to the man. (Akan: Boadi 1971:23 (18))

Definite possessive predication shows one less kind of encoding than indefinite possessive predication: There seem to be no PSE-oblique definite possessives. I do not address this question here due to space constraints. For discussion, see Tham (ms).

\subsection{Predication type in possessive sentences}

Possessive predication sentences may also be ascriptive, equative, or presentative.

\section{Ascriptive and equative meanings for possessives}

Partee and Borschev (2001) argue that a definite possessive predication sentence such as The pen is Pat's has two possible analyses. The genitive NP could be predicative, with a type $\langle e, t\rangle$ meaning $((26))$, i.e. the sentence would be ascriptive.

(26) Pat's: $\lambda x\left[\mathrm{R}_{P O S S}(\mathrm{Pat})(\mathrm{x})\right]$; type: $<e, t>$ (Partee and Borschev 2001: (31))

Alternatively, it could be understood as an elliptical NP, potentially ranging over type $e$, type $\langle e, t\rangle$, or type $\langle e,\langle e, t\rangle\rangle$ in an equative sentence. Partee and Borschev (2001) propose that definite possessive predication in Russian allows both ascriptive and equative options. In such sentences, the PSR may be in instrumental case in the past tense (27a), or it may be nominative (27b) (Partee and Borschev 2001). There is a contrast between nominative and instrumental PSRs: The instrumental PSR is synonymous with a full adnominal possessive (27a). If the PSR is in nominative case, however, it cannot be replaced by an adnominal possessive (27b). 
(27) Russian definite possessive predication

a. Éta btrana kyla kogda-to

that-FEM.NOM.SG country-FEM.NOM.SG was-FEM.SG once

moej Stranoj

my-FEM.INSTR / my-FEM.INSTR.SG country-FEM.INSTR.SG

That country was once mine / my country ('possession' or citizenship)

b. Éta strana byla kogda-to

that-FEM.NOM.SG country-FEM.NOM.SG was-FEM.SG once

moja $/ *_{\text {moja strana }}$

my-FEM.NOM.SG / my-FEM.NOM.SG country-FEM.NOM.SG

That country was once mine / my country' ('possession' only)

This indicates the instrumental PSR in (27a) is an elliptical NP, and the possessive sentence is an equative one. The nominative PSR in (27b), however, would be a predicate of type $\langle e, t\rangle$, and the sentence is ascriptive. Partee and Borschev (2001) further support this distinction with data from Polish and German.

\section{Presentative}

Indefinite possessive predication sentences in various languages show a definiteness effect on the PSE nominal, and are presentative according to the working definition proposed above. Partee (1999) shows that English have, like the pivot in existential there sentences, is infelicitous with definite or "strong" NPs (Milsark 1974):

(28) John has a/some/three/at least three/several/many/a few/no/few/at most three/exactly three sisters.

(29) \#John has the/every/both/most/neither/all/all three/the three sisters. (adapted from Partee 1999 (4)-(6))

Tham (2006) argues that this DE is imposed by possessive have, reflecting its presentative function. Have sentences with an indefinite complement nominal e.g. Pat has a sister/a crooked nose/a pen allow two kinds of interpretations. The most natural interpretation would be the relational interpretation with kinship and bodypart nominals such as a sisterla nose. With a non-relational nominal, e.g. pen, the obvious interpretation is one of ownership or some kind of control, disposal rights, etc. I consider these as core possessive relations.

Other interpretations are possible: E.g., if some friends had adopted puppies from the same litter, Pat has a sister could well mean Pat adopted a puppy that is sister to a friend's puppy. Similarly, when comparing gains from a raffle, Pat has a pen could mean that Pat had drawn a pen in the raffle. But these interpretations, unlike core possessive relations, clearly require a context. Such contexts also allow definite complements to have, e.g. Pat has the sister. Yet, even in such contexts, indefinite complements still allow core possessive meanings: Pat has a sister in 


\section{Possession as Non-Verbal Predication}

the puppy context could still mean "Pat has a female sibling", e.g. if followed by She got a puppy from the same litter. That is, indefinite complements to have alone consistently yield core possessive meanings across contexts, tying possessive predication to the DE and in turn, to a presentative function.

Similar DEs in possessive clauses have been noted, e.g. in German (Heine 1997, 30) and Japanese (Tsujioka 2002). The preceding discussion shows that possessive sentences, like NVPSs, may be ascriptive, equative, and presentative.

\subsection{Predictions: other encoding strategies}

The non-verbal analysis predicts that other kinds of NVPSs should be found in possessive predication. Some of these structures are also compatible with Stassen's existential clause sequence approach, though the two approaches differ on others.

\section{NP juxtaposition}

Both the non-verbal and existential clause sequence analyses predict the possibility of possessive clauses that simply juxtapose PSR and PSE nominals (30) (Stassen 2009, 82-89).

\section{(30) ngumban-da wakatha maku kiyarrng-k \\ 2SG.POSS-NOM sister.NOM sister-in-law.NOM two-NOM}

Your sister has two sisters-in-law. (Kayardild: Evans 1995, 318 (9-24))

The non-verbal analysis directly predicts such structures. As far as I understand, for the existential clause sequence analysis, these should only arise in a language where there is no existential verb, which in turn is supposed to be possible only in a language with no overt copula (Stassen 1997). Possessive sentences of this shape are thus ambiguous with nominal predication interpretations, although real world knowledge frequently constrains the interpretation to one or the other. This ambiguity may be why it is rare to find such possessive sentences (Stassen 2009).

\section{Conjunction}

Stassen (2009:89-94) reports the use of conjunction in possessive predication "in a small number of unrelated languages". The morpheme dé in the Galela possessive (31) corresponds to a clausal conjunction morpheme (ibid. p90 (105a)).

$$
\begin{aligned}
& \text { Ngohi dé ai tahu-ka } \\
& \text { 1SG and my house-already }
\end{aligned}
$$

I have a house.

(Galela: Van Baarda 1908:135, cited in Stassen 2009:90 (104))

In the existential clause sequence analysis, the conjunction marker presumably reflects the presence of a clause sequence. The non-verbal analysis does not directly 
predict these structures, but since a conjunction morpheme is a relational non-verbal morpheme that could potentially develop predicative status, its use in possessive encoding can be accommodated. Since conjunctions are typically non-predicative, the non-verbal approach would predict this option to be infrequent, whereas this rarity seems somewhat unexpected under the clause sequence analysis.

\section{Affixation}

The non-verbal analysis also predicts other options such as affixal stragies in languages where agglutinative structures are prevalent. Chiquitano, a genetically isolated language spoken in Bolivia (Adelaar et al. 2004:477ff), expresses possessive predication (32c) by "prefixing a noun with a person marking and adding $-k a$ at the end" (ibid. p487). (The noun describes the PSE, person marking indexes the PSR.)

(32) Chiquitano: Affixal strategy in possessive encoding
a. $\quad$ triabo $\stackrel{2}{s}-n^{y} i$
captain-1SJ.SG
b. iriabo $\stackrel{2}{s-k a-n^{y} i}$
captain-ND-1SJ.SG
c. $\quad$-po: $-k a$
1SG-house-ND
I am a captain.
I have become a captain. I have a house
(Adam and Henry (1880, 45), cited in Adelaar et al. $(2004,487)$ )

McGregor (2001) notes that Jabirrjabirr, a Western Nyulnyulan language spoken on the Dampier Land peninsula in Australia, uses an applicative morpheme in possessive predication. It is not immediately clear how these examples should be handled under the existential clause sequence analysis.

\section{Adjectival predicates in possessive predication?}

Finally, Stassen (2009:137ff) suggests that With possessives may in some languages become reanalyzed as an intransitive predicate that could be seen as adjectival.

The proposal is formulated somewhat indirectly. In different languages, adjectives may pattern morphosyntactically like nouns or like verbs (Stassen 1997). Drawing on this division, Stassen $(2009,139-140)$ demonstrates that, in languages where a With possessive has been reanalyzed to an intransitive predicate: If adjectives pattern like verbs (e.g. they directly combine with tense and agreement markers without a copula present), the possessive predicate also patterns like a verb. If adjectives pattern like nouns (they cannot directly combine with tense and agreement markers), the possessive predicate also patterns like nouns.

The point is subtle and needs further investigation, but if correct, this suggests possessive predicates show the whole range of non-verbal predicate categories: nominal (e.g. NP-juxtaposition), oblique phrase (adpositional or oblique case), and adjectival! This conclusion would further support the non-verbal analysis. 


\section{Possession as Non-Verbal Predication}

\section{Conclusion}

To recapitulate, the non-verbal analysis of possessive predication, extended with light verbs, (i) provides a principled account for the morphosyntactic categories of indefinite possessive predication in Stassen (2009), and (ii) accounts for definite possessive predication in the same way, using (iii) existing generalizations about NVPSs without special mechanisms particular to possession. This suggests that the non-verbal predication structures in a language may be the key to predicting the encoding options for possessive predication in that language. Finally, (33) compares the non-verbal analysis with the typologies of Stassen (2009) and Heine (1997).

(33) The non-verbal analysis, Stassen (2009) and Heine (1997) compared

\begin{tabular}{lll}
\hline \multicolumn{1}{l}{ Non-verbal analysis } & Stassen (2009) & Heine (1997) \\
\hline \hline \multicolumn{2}{c}{ INDEFINITE POSSESSIVE PREDICATION } \\
\hline \hline Oblique PSR & Locational & Locative, Genitive, Goal \\
Oblique PSE & With & Companion \\
Light verb & Topic, Have & Topic, Action \\
\hline NP NP & Clause sequence & NA \\
Relational non-verbal morpheme & Conjunction & NA \\
Affixal & $?$ & NA \\
\hline \hline \multicolumn{3}{c}{ DEFINITE POSSESSIVE PREDICATION } \\
\hline \hline Oblique PSR & NA & Equation \\
Oblique PSE predicted, not observed & NA & not mentioned \\
Light verb & NA & not mentioned \\
\hline
\end{tabular}

Acknowledgements: Thanks to Beth Levin for helpful comments on the talk handout, and to Line Mikkelsen, Xie Zhiguo, Joost Zwarts and members of the BLS 39 audience for thought-provoking questions on the talk. Any errors are solely mine.

\section{References}

Abbott, Barbara., 1992. Definiteness, Existentials, and the 'List' Interpretation. In Proceedings of Semantics and Linguistic Theory II.

Adam, Lucien and Henry, Victor, 1880. Arte y vocabulario de la lengua chiquita con algunos textos traducidos y explicados compusetos sobre manuscritos inéditos, Bibliothèque linguistique américaine, volume 6. Paris: Maisonneuve.

Adelaar, Willem F.H., Muysken, Pieter, and Anderson, S.R., 2004. The Languages of the Andes. Cambridge, UK: Cambridge University Press.

Aissen, Judith, 1975. Presentational There-Insertion: A Cyclic Root Transformation. In Proceedings of the 11th regional meeting of the Chicago Linguistics Society, 1-14.

Barwise, Jon and Cooper, Robin, 1980. Generalized Quantifiers and Natural Language. Linguistics and Philosophy 4:159-219. 
Shiao Wei Tham

Boadi, L.A., 1971. Existential Sentences in Akan. Foundations of Linguistics 7:1929.

Bresnan, Joan, 1994. Locative Inversion and the Architecture of Universal Grammar. Language 70(1):72-131.

Clark, Eve V., 1970. Locationals: A Study of the Relations between 'Existential', 'Locative' and 'Possessive' Constructions. Working papers on language universals 3:L1-L37.

Dik, Simon, 1980. Studies in Functional Grammar. London: Academic Press.

Evans, Nicholas, 1995. A Grammar of Kayardild. Berlin: Mouton de Gruyter.

Freeze, Ray, 1992. Existentials and Other Locatives. Language 68(3):553-595.

Heine, Bernd, 1997. Possession: Cognitive Sources, Forces, and Grammaticalization. Cambridge, UK: Cambridge University Press.

Hengeveld, Kees, 1992. Non Verbal Predication. Theory, typology, diachrony. Berlin: Mouton.

Higgins, F.R., 1979. The Pseudo-Cleft Construction in English. New York: Garland.

Keegan, J.M., 1997. A Reference Grammar of Mbay. Munich: LINCOM Europa.

Li, Charles N. and Thompson, Sandra, 1981. Mandarin Chinese: A Functional Reference Grammar. Berkeley, CA: University of California Press, second edition.

Lyons, John, 1968. Introduction to Theoretical Linguistics. Cambridge University Press.

McGregor, William B., 2001. Non-Verbal Predicative Possession in Nyulnyulan Languages. In Jane Simpson et al., ed., Forty Years On: Ken Hale and Australian Languages, 337-352. Canberra: Pacific Linguistics.

McNally, Louise, 1997. A Semantics for the English Existential Construction. New York: Garland Publishing.

Milsark, Gary, 1974. Existential Sentences in English. Ph.D. thesis, MIT.

Mohanan, Tara, 1994. Argument Structure in Hindi. Stanford, CA: CSLI Publications.

Naït-Zerrad, K., 2001. Grammaire moderne du kabyle. Paris: Karthala.

Partee, Barbara, 1999. Weak NP's in HAVE sentences. In J.G̈erbrandy et al., ed., a Liber Amicorum for Johan van Benthem on the Occasion of his 50th Birthday. Amsterdam: CD-Rom, University of Amsterdam.

Partee, Barbara and Borschev, Vladimir, 2001. Some Puzzles of Predicate Possessives. In R.M. Harnish and Istvan Kenesei, eds., Festchrift for Ferenc Kiefer, 91-117. Amsterdam: John Benjamins.

Pustet, Regina, 2003. Copulas: Universals in the Categorization of the Lexicon. Oxford: Oxford University Press.

Safir, Kenneth J., 1987. What Explains the Definiteness Effect? In Eric J. Reuland and Alice G.B. ter Meulen, eds., The representation of (in)definiteness, 71-97. Cambridge, MA: MIT Press.

Seiler, Hansjakob, 2001. The Operational Basis of Possession: A Dimensional 


\section{Possession as Non-Verbal Predication}

Approach Revisited. In Irène Baron, Michael Herslund, and Finn Sørenson, eds., Dimensions of possession, 27-40. Amsterdam: John Benjamins.

Stassen, Leon, 1997. Intransitive Predication. Oxford: Oxford University Press. Stassen, Leon, 2009. Predicative Possession. Oxford: Oxford University Press.

Stokes, Bronwyn, 1982. A Description of Nyigyina: a language of the West Kimberley, Western Australia. Ph.D. thesis, Australian National University.

Tham, Shiao Wei, 2006. The Definiteness Effect in English have sentences. In Pascal Denis et al., ed., Proceedings of the 2004 Texas Linguistics Society Conference, 137-149. Somerville, MA: Cascadilla Proceedings Project.

Tham, Shiao Wei, ms. The Forms of Possessive Predication. Wellesley College.

Tsujioka, Takae, 2002. The Syntax of Possession in Japanese. New York: Routledge.

Van Baarda, M. J., 1908. Leidraad bij het bestuderen van 't Galela'sch dialect op het eiland Halmaheira. The Hague: Martinus Nijhoff.

Shiao Wei Tham

Department of East Asian Languages and Culture

Wellesley College

106 Central Street,

Wellesley, MA 02481-8203

stham@wellesley.edu 